\title{
Flightlines: exploring early readers for children about the refugee experience
}

FORUM: for promoting 3-19 comprehensive education, 49(3), pp. 289298

\author{
Julia Hope, Goldsmiths College
}

Much has been written about children's literature that deals with war, and specifically the holocaust, but very little has been said about the portrayal of the refugee experience in children's books, which is now developing as a significant genre of its own. The rapid growth in these books, which are aimed at all ages, has not been documented separately and yet there are compelling messages that derive from them about citizenship, tolerance, respect and integration, and well as the enduring nature of the human spirit in the face of terrible circumstances. In this article I will be focussing particularly on books about the refugee experience written for the younger reader, and their suitability for the age group they are aimed at.

\section{Introduction}

It can be, and often is, suggested that books about controversial and uncomfortable subjects are not suitable for young children. However in recent years we have seen a growth in the number of texts published in English which seek to confront difficult subject matter that may be troubling for younger children, and through the medium of literature, help them to deal with those issues. So, for example, we have books about disability, family separations, bereavement and the effects of war. By bringing out into the open such problem areas, while reading with a parent, or a teacher in a class setting, children are able to discuss the issues raised in a safe and supportive environment, and begin to deal with themes that may reoccur throughout their lives.

Within this perspective, we seem to have come full circle. Much early literature for children had a religious slant, and sought to affirm the need for faith and goodness, through alarming stories in which children were lost, kidnapped and fell seriously ill and sometimes died. The Victorians didn't believe in sparing their young folk, and the message of Christianity and the need for kindness was driven home in many ways, one such being the medium of literature. As religious didacticism receded, children's literature became less to do with the teaching of morals and behaviour, and more for enjoyment and escapism. Heavy handed proselytising was out and fantasy and freedom were in.

This was particularly true of children's literature about war. When The Silver Sword by Ian Serrallier, arguably the first children's book about refugees, was published in 1956, it was not readily welcomed into the existing "canon" of children's literature. When the book was made into a television serial in 1957, "many people wrote to the head of BBC children's television protesting that war was not a suitable subject for children - that it was not right to show them this terrible chapter of human history" (Jane Serraillier Grossfeld, 1993 edition, P.192). Perhaps post-war, the feeling was 
that children needed to enjoy childhood, free from the worries and pressures of adult life. However, more recently publishers, writers, teachers and parents have come to realise that there is a place for the more hard hitting fiction that we now see emerging in abundance today. Children need to understand the reality of modern life to deal with the circumstances they live in, or to appreciate the situation of others less fortunate than themselves.

Since the appearance of The Silver Sword fifty years ago, we have seen the emergence of an increasing amount of children's literature about war, and in recent years, the appearance of the refugee child in books for the young. Now it is possible to identify around 60 books written for children in English, or translated, which explore the refugee experience and embrace stories set in locations as far afield as Bosnia, Somalia, Eritrea, Nigeria, Iran, Iraq, Afghanistan, and Vietnam. As expected, these books reflect the waves of migration experienced by host countries in recent years, as conflicts escalate and globalisation and improved travel lead to more people claiming sanctuary in other countries. We are now looking at a situation where there are $12,000,000$ refugees worldwide, and this newly emergent genre in children's literature reflects reality.

It is beyond the scope of this article to interrogate all 60 plus texts, and so I will narrow the field to consider children's literature about refugees written for the younger years. As a teacher in the UK for many years, I am mindful of the demarcation of "Key Stages" we have in Britain at the present moment. In this way I am therefore focussing on Key Stage One children - that is from 5-7 years old. The books I have chosen to look at therefore represent the earliest examples of books concerned with persecution and flight that children might have read to them by parents, grandparents or teachers, and might also be able, at the upper end, to read to themselves.

\section{Picture Books}

One of the most interesting developments in UK publishing is the presence of new books about refugees written for younger readers in the form of picture books. This is not a new phenomenon in the US, as during the 1990s we have three books rooted in very similar experiences. The Lotus Seed (Garland, 1993) was a response to the large community of Vietnamese people who fled as refugees and settled in America, after a prolonged war of independence, followed by a civil war in which America became mired. This is a simple and beautiful story, illustrated by a Japanese artist, Tatsuro Kiuchi. Although not Vietnamese herself, we are told on the dust cover that Sherry Garland's "interest in Vietnam comes from her close association with Vietnamese families". The contextual information also explains that this is "an emotional tale of a Vietnamese family forced to flee from their homeland to escape a devastating civil war." The story begins when the narrator's grandmother keeps a lotus seed from the emperor's palace garden as the old regime falls. As events darken, the book tells graphically, in words and pictures, of the family's flight from war, to settle in America, where the lotus seed was accidentally planted and flowered, a metaphor for the adaptation and hope for the future embodied in the younger generation of the family. 
Two other books from the US are remarkable in their similarity. The Whispering Cloth (Deitz Shea, 1995) and Dia's Story Cloth (Cha, 1996) both tell the story of the Hmong people of Laos, persecuted for fighting alongside the Americans. Tens of thousands of Hmong fled to Thailand, where they spent many years in refugee camps until removal to the US. Both stories use the story cloths stitched by the Hmong as the basis for their tale, but whereas Pegi Deitz Shea's connection with the Hmong is unclear, Dia Cha is Hmong herself, and the book uses a story cloth stitched by her uncle and aunt in a Thai refugee camp as illustration. While the story of flight is similar in both books, the former is aimed much more at younger children and has a fictional protagonist who they can identify with, while the latter is directly autobiographical and is pitched at a much older age group. Both books have surrounding contextual information to inform the reader (whether it be teacher, parent or child) of the geographical and historical background to the stories, but Dia Cha's approach is much more academic in nature. The two books form an interesting contrast and highlight different approaches, but also similarities when dealing with the refugee experience. What becomes abundantly clear when reading such texts is that they have a clear intention - to highlight the plight of a particular group of people, and to educate others to understand their culture, traditions and predicament.

It was not until 2002 that a picture book especially written about refugees was launched by the British publishing world. Specially commissioned by the publisher Frances Lincoln, Mary Hoffman's The Colour of Home has enjoyed enormous popularity and is visible in many classrooms in London and elsewhere. It was closely followed by Petar's Song by Pratima Mitchell in 2003, from the same publisher. Both books tell the story of a boy fleeing from the effects of war, with part or all of his family, and settling in a new country. In both cases, resettlement is not easy, but the resilience of each child leads them to eventually embrace their new lives in a spirit of hope. The two books have remarkable and well-known illustrators, Karin Littlewood and Caroline Binch, respectively, who add detail, authenticity and artistry to the finished product. However they contrast in an important way, which serves to throw light on the process and purpose of writing about the refugee experience.

The Colour of Home is very firmly located in a geographical framework. The story starts in Somalia, and we follow Hassan on a boat to Kenya and then by plane to Britain. In this way, the book is a useful starting point for a discussion on the possible experiences of real-life refugees whose journey can be traced on a map, and whose possible reasons for flight are graphically illustrated. Petar's Story, however, is not located, although it is probably set in the Balkans. We are told that Petar is Christian, which adds further ambiguity, as many refugees from the Balkan regions were Muslims fleeing from Christian oppression. We also do not know where he escapes to, although it is possibly Austria, or a similar Central European country. For these reasons I would suggest that Petar's Song limits its own possibilities as a text to highlight the refugee plight. Although it can be used to discuss the affective side of the experience, as Petar has to leave his father behind, it cannot become the basis for any geographical or historical discussion of events that may lead to flight. I would suggest that Mitchell has made the location deliberately ambiguous, so as not to inflame possible tensions within Balkan groups present in British classrooms. However by making Petar Christian, she places him as 'other' to the experience of many Eastern European refugees in the UK. 
I have argued that books locating the child's experience in a particular country or geographical location and political conflict are more useful as a teaching tool than those that don't. However a further picture book from the US, Playing War (2005), is eminently successful in its message without pinpointing the refugee experience. The dust cover states that "Tilbury House publishes children's books that empower children, build empathy, and spark curiosity." The mission statement is clear, and Kathy Beckwith's book is effective within the simple message it sets out to make. When a group of children "play war" a newly arrived child in the community becomes upset and tells the story of how his house was bombed "by mistake" and his mother, father, and little brother were killed. His uncle rescued him and brought him to the US. In this way the book has a different intention from the others, to highlight the hideousness and random nature of war, and the unsuitability of playing it for fun, and although it describes a refugee scenario, the refugee experience is not the central theme. Because of this, the precise location of the tragedy is not important and the book can still function as a powerful discussion starter to think about the futility of war. This is further aided by the fact that we encounter Sameer, the refugee child, amongst and contrasted with the other children. Their changed attitude to war is just as important to the tale as the experience of Sameer.

\section{Early Readers}

Another area of interest is the emergence of early readers for Key Stage One - the 5-7 year old age group, in the last decade or so. These books are smaller in size and characterised by greater dominance of text over pictures. They do all still contain pictures, and could easily be read to a class of children, though with less visual effect than picture books. Again we begin in North America with From Far Away (1995) by Robert Munsch and Saoussan Askar. This book is small, simple and intriguing. It is published in the US by a Canadian group called Annick Press Ltd. A visit to the website displays a company committed to developing good literature which deal with human rights questions. They state: "Annick books are valued companions as kids grow into an awareness of themselves and the larger world around them. When a book resonates with youth, it succeeds in opening doors to the imagination; it can reveal truths and new ways of looking at one's life or the larger community."

One of their founder writers is Robert Munsch, author of the famous Paper Bag Princess (1980), which aims to counter gender stereotypes in fairy tales. He also coauthors From Far Away with Saoussan Askar, and the back cover reveals that she was only seven when she wrote a series of letters to Munsch that inspired the book. We are also informed that she came to Ontario from Beirut when she was five years old, and the story reveals that her family were refugees fleeing in 1991 from ongoing conflict in Lebanon. The story starts dramatically with a simple description of the effects of war on Saoussan's family, and the reason for flight. Her father left first and then sent plane tickets to Canada. On arrival in her new school Saoussan tells of her confusion and loneliness caused by language barriers, and how she developed ways to overcome these obstacles. She also highlights cultural differences through her misunderstanding of Halloween traditions, but surrounded by kindness from her teacher and peers she becomes academically successful and fully integrated into school life. 
This is a useful text for several reasons. As it is autobiographical in nature, with a photo of Saoussan shown on the back, the book has an immediacy and plausibility that others may lack. Personal testimony is an ideal medium for communicating such experiences, and when they can be first hand the effect is much more convincing. Furthermore, the information contained on the back cover and in the text locates the experience of the little girl firmly in easily identifiable geographical locations, which can form the basis of further discussion and identification. The usefulness of this contextual information has been noted earlier.

We now move to the UK with the publication in 1996 of Helen Dunmore's Amina's Blanket. Again, Dunmore is an author of international renown, writing many awardwinning books for adults as well as children. The story in question was originally published in hardback by Heinemann, but later included in the Banana Books series, from Egmont Books Ltd., designed as a starting point for early readers. The book is complex in structure, but uses fairly simple language, suitable for reading to a class or for "newly fluent readers". It contrasts the lives of Josie and Amina through the device of a blanket, knitted in squares by Josie's class and sent to a homeless person's shelter in an unnamed city which is war-torn. Dunmore uses the blanket-making activity as a means to convey the reality of war, explaining such terms as "shells" for children who may easily misinterpret the meaning. As Josie sleeps under the newly constructed blanket she dreams of meeting Amina, who appears to live in a city such as Sarajevo, subject to heavy shelling and covered in snow. As the two girls huddle under the blanket a huge explosion rocks the flat, which bursts into flames. This is an extremely vivid and alarming sequence, and conveys the reality of what children caught up in the middle of urban warfare may well experience. The book is hardhitting and does not hold back in its determination to expose the reader to the full force of the situation. The illustrations added by Paul Dainton in 2000, are vivid and dramatic, adding force to the well-crafted words.

It is interesting to note that Amina's Blanket, like Petar's Song, is again not given a geographical location, and this would fuel the theory that Balkan conflicts are often not located, in that they are quite close to home, and may cause problems in the British classrooms where they might be read. However it is useful that Amina's Blanket is part of a series of books which are commonly ordered as a set by primary school teachers. In this way it might find its way onto classroom shelves more easily than if marketed as an independent title, and would therefore reach more readers than otherwise. The same is true of The Best Prize of All (2002) by Saviour Pirotta, a Maltese writer of children's books. As part of a series of "Celebration Stories" about religious festivals, this tale of a Harvest competition, makes up the Christian element of the collection. However there are criticisms of the book which would suggest that it might be negative in its portrayal of refugees, and therefore not a welcome addition to classrooms nationwide.

Although The Best Prize of All culminates in a celebration involving host and refugee communities, we are introduced to the refugee experience through abrupt and negative language:

"As they passed the gates of the disused army barracks at the edge of the village, Linda waved at a girl in a shapeless red dress and green wellies that came up to her knees. The girl waved back shyly but did not smile. She was a 
refugee from Eastern Europe. Her family was staying in the barracks, along with some other refugees. For weeks, Linda had seen her standing by the gates, her big, dark eyes full of sadness. She seemed lonely and lost. Perhaps she was missing her friends back home, Linda thought." (P. 10-11)

Here we are being confronted with a stereotype and although there is sympathy, there is a danger that it may also become patronising. When Grandad's prize pumpkin is stolen by a shadowy figure, the "otherness" of the refugees is hinted at still further. One wonders how any Eastern European child, refugee or not, sitting in a class at story time would be feeling at this point, the blanket geographical reference being over-generalised and unhelpful in this case. Furthermore, children who are refugees may experience negative emotions when presented with such reading material. It is never useful to be cast as such a victim, and although the same comment could be made about all the books discussed, most have important features which display the resilience of refugee children, or contain some humour and richness, which makes the tale worth telling, despite its possibly disturbing subject matter.

Even when the refugee family return the pumpkin and apologise for its disappearance they are not accorded much dignity. The mother speaks in obvious pidgin English, and the contrast between the two girls is spelled out in painful clarity:

"Linda looked at Anya. She seemed so fragile in her red dress, so lost and far away from home. And all she wanted was a slice of fried pumpkin with sugar. Linda felt herself go red in the face. She had so much to be thankful for -a loving family, a good school, food, clothes, toys, books, a roof over her head.'

Here we find pity rather than empathy, something that no child wants channelled in their direction. Although the book ends with a Harvest celebration refugee-style in a barn near the army barracks, the message is still laboured, the main purpose of the book being the giving thanks for what you have, rather than a realistic portrayal of the refugee experience, that children can use to inform and sensitise themselves to the world around them.

In marked contrast we find a new and powerful book on the market, Christophe's Story (2006) written by Nicki Cornwell and published by Frances Lincoln, as previously mentioned. Simply written and illustrated again by Karin Littlewood, we follow Christophe as he develops the confidence to tell his story to the class. His family were attacked in the Rwandan genocide and his younger brother killed, before they fled to safety - not a subject that some consider suitable for a children's book. However Cornwell deals with the background events in a matter of fact, but detailed way, that give children the feeling she is hiding nothing. Here we have a specific geographical location specified in the text, and authenticity added by the use of French from time to time, to heighten the understanding of Christophe's relocation and isolation. There is even an explanatory footnote to provide further contextual information. But what is particularly heartening in this book is the pride that Christophe feels as he recounts his experiences. Refugee children have often been brave in the face of danger, and should be encouraged to celebrate their strengths. As Christophe gets carried away in telling his story, an adult reader may well smile to themselves, recognising the way children everywhere bask in glory, especially if it is their own. But he, himself, fully realises the dramatic significance of the moment: 
"Christophe lifted up his shirt and his vest and showed off his bullet burn.

'Wow!' gasped the children.

Christophe felt a grin beginning to spread over his face. No, he mustn't smile! It was no time to smile now!"

Again the story ends on a positive note, Christophe having dealt with bullying, overcome his communication problems, and successfully recorded his story in a way which he feels would please his grandfather, who he discovers has just died. As the whole school has an opportunity to hear and respond to his tale, and his book is published, a new sister arrives for Christophe. The tale within a tale is a useful device, and the teacher serves to make explicit the power of books to disseminate information and educate an audience beyond the reaches of personal contact.

\section{Conclusion}

In this article I have examined picture books and early readers for young children that encompass the refugee experience. In a short overview it can be seen that pioneering books in the area were developed in the US, but that more recently the UK has published some high quality texts, based on events and locations that can offer some in-depth understanding of the plight of refugee children. These books serve a dual function, to educate all children about the experience of persecution, flight and resettlement, as well as reassuring refugee readers that there is new life and hope for the future in an adopted country.

Those who may suggest that such subject matter is unsuitable for young children are increasingly in the minority, while many enthusiastically embrace such books as a way of raising and highlighting issues that are difficult to broach in any other way. What is clear is that sensitivity is required in their use, and that books need to be well written, realistically illustrated, and properly researched. It is of paramount importance that refugees are depicted positively, that there is empathy but not pity, and that, where possible the situations described are located geographically and politically to make most impact in mirroring real life scenarios. If all these factors are considered, books such as the ones discussed above, can make a significant contribution in broadening the understanding of non-refugee children and validating the experiences of refugees in our classrooms. 


\section{Bibliography}

Beckwith, K., (2005) Playing War (Gardiner, Maine, USA, Tilbury House)

Cha, D., (1996) Dia's Story Cloth (New York, USA, Lee \& Low Books Inc.)

Cornwell, N., (2006) Christophe's Story (London, Frances Lincoln)

Deitz Shea, P., (1995) The Whispering Cloth (Honesdale, Penn, USA, Boyds Mills Press)

Dunmore, H., (1996) Amina's Blanket (London, UK, Heinemann)

Garland, S., (1993) The Lotus Seed (Orlando, Florida, USA, Harcourt Brace \& Co)

Hoffman, M. and Littlewood, K. (2002) The Colour of Home (London, Frances Lincoln Ltd).

Mitchell, P. (2004) Petar's Song (London, Frances Lincoln Ltd).

Munch, R. (1980) The Paper Bag Princess (USA, Annick Press Ltd.)

Munch, R., \& Askar, S., (1995) From Far Away (USA, Annick Press Ltd.)

Pirotta, S., (2002) The Best Prize of All (London, Hodder Wayland)

Serraillier, I. (1956) The Silver Sword (London, Jonathan Cape) and (1993 London, Penguin Books).

\section{Websites}

http://www.annickpress.com/about/index.html (last accessed $15^{\text {th }}$ June 2007) 